\title{
VENTAJAS DE COLORACION DE MAY GRUNWALD GIEMSA EN LA PROFILAXIS DEL CARCINOMA CERVICAL
}

\author{
Dr. Gilberto Angel M.*
}

\section{Introducción}

Quien haya trajinado un poco en el terreno hematológico, conoce muy bien que en el estudio de la medula ósea normal y patológica, encuentra numerosas células jóvenes con estructuras cromáticas donde la presencia de los ácidos DNA (Desoxirribonucleico) y RNA (Ribonucleico) es muy manifiesta y nítidamente demostrable con la coloración de Giemsa. Aprecia nucléolos, finas trazas de cromatina, límites más o menos nítidos, anisonucleosis, polimorfismo nuclear (1), pérdida de la relación núcleo-citoplasma, policromasia nuclear, mitosis (2), vacuolización, etc., etc., características normales en las células inmaduras de la medula ósea, pero muy similares a las que encontramos en las células malignas (3), (11).

En literatura europea encontramos artículos (4), texto (5) y atlas (6), relacionados con citología vaginal exfoliativa, con modificaciones del Giemsa lento, progresivo o instantáneo, con resultados muy demostrativos. El Giemsa por ser selectivo en la identificación de la Trichomona (7), (12), (Técnica de Sorel) las destaca nítidamente y bien sabemos la importancia de este factor en el estudio citológico. De todos los pató- logos es conocido el cuadro de displasias, actividades ectocervicales simulando en ocasiones cuadros de Carcinoma in situ (23), en biopsias cervicales con Trichomoniasis concomitante, encontrándose posteriormente cuadros normales 0 inflamatorios, con la desaparición de la Trichomoniasis.

Globalmente, también podemos apreciar con esta coloración el nivel estrogénico, pues diferencia fácilmente células endocervicales, endometriales, basales, para-basales intermedias y superficiales y bien sabemos la frecuencia de falsas citologías positivas - tipo III con niveles estrogénicos muy bajos $(8,13)$.

\section{Coloración de Papanicolaou}

La magistral publicación de G. N. Papanicolaou con la colaboración del ginecólogo Traut en 1941 (3), fue la encargada de revivir el entusiasmo sobre los estudios citológicos; publicados a fines del siglo pasado (1882) (5), por Paul Erlich en investigaciones tomadas de derrames serosos, esputo, líquido ascítico usando la coloración de Giemsa. Cali. 
Innumerables artículos se han publicado en los 28 años posteriores a su primera comunicación, reconociéndose en todas, la importancia auxiliar en el diagnóstico del carcinoma, dándole al método con toda justicia, el nombre del autor que revivió sus bases, amplió su campo, profundizó su estudio e interesó en el mundo entero al conglomerado científico que trata de encontrar con su sistema, un campo preventivo en el terreno neoplásico.

Los mejores contrastes, la mejor definición nuclear, los detalles citoplasmáticos más suaves y la más nítida estructura celular, la encontramos en la coloración ideada por $\mathrm{Pa}$ panicolaou (3). Quien esté familiarizado con su técnica, no encuentra dificultad en realizar sus 23 pases en diferentes líquidos, ampliamente compensados con la nitidez, resolución y bienestar, que produce al observador una coloración de este tipo bien ejecutada.

Sinembargo, en nuestro medio siempre carente de recursos económi$\cos$ en los Hospitales, consulta externa, consultorios populares, centros de salud, etc., todos ellos encaminados a prestar su colaboración a las clases económicamente débiles, no es fácil hacer una verdadera campaña citológica con la colaboración de Papanicolaou. El gran costo que representa realizar millares de citologías, justamente en pacientes que por sus condiciones higiénicas, nutritivas $y$ sociales, son las encargadas de aumentar la incidencia del carcinoma cervical, priva en los Directores de emprender campañas intensas en la prevención y tratamiento precoz del carcinoma cervical.

Con este trabajo, no pretendemos convencer, ni demostrar que coloraciones diferentes a la de Papanico- laou, sean mejores en el estudio citológico. Solo queremos invitar a citólogos y patólogos a verificar simultáneamente en sus estudios citológicos, coloraciones de Papanicolaou y Giemsa, para que comprueben con su propia experiencia que esta última, con un poco de práctica, ofrece desde el punto de vista diagnóstico, la misma seguridad, facilidad y elementos de juicio que la primera, con un costo de unos pocos centavos en comparación a la de Papanicolaou, que en nuestro medio es cerca de $\$ 15,00$.

\section{Técnica de la coloración de Giemsa}

Una de las principales ventajas de esta coloración, es que no es necesaria la fijación previa en alcohol-éter, como lo es en la de Papanicolaou para evitar la hidratación celular. El extendido se deja secar al medio ambiente y se puede remitir al Laboratorio en un pequeño estuche de cartón, o simplemente envuelto en papel poniendo previamente en uno de los extremos del portaobjeto, uno de los clips usados en papelería, para evitar la adhesión del papel a la preparación. La fijación se verifica en el Laboratorio, la que se puede hacer en las primeras 24 horas, sin que se aprecie ninguna alteración celular que afecte el diagnóstico posterior, pues el Giemsa no revela la hidratación celular, que es tan manifiesta en la coloración de Papanicolaou cuando la preparación no se fija inmediatamente se toma. Los pases en la coloración de Giemsa, son los siguientes:

1. Fijar la preparación con alcohol metílico, durante 3 minutos.

2. Botar y cubrir la preparación, con solución de Giemsa recién preparada. No mayor tiempo de una hora. 
(Una gota de solución madre de Giemsa por cada centímetro de agua).

3. Dejar obrar el colorante por 15 - 20 minutos.

4. Secar y pasar sobre el portaobjeto una gota de aceite de cedro, que se extiende con un palillo. ( $\mathrm{Si}$ la placa se desea conservar, se puede cubrir con laminilla).

\section{Importancia de una buena toma}

Quizás un factor tan importante como la coloración y la interpretación citológica, radica en la manera como se toman las muestras pero desafortunadamente no se le da la importancia que merece. Este factor hace que tanto con la coloración de Papanicolaou como con cualquiera de las usadas, se obtenga el error de falso negativo por muestra mal tomada. En cualquier actividad de Laboratorio, la calidad y resultado del análisis depende primordialmente de cómo se toma la muestra. Con una extensión de sangre mal verificada, con campos superpuestos, mal extendida, muy gruesa etc. el diagnóstico de una leucemia, un paludismo o una simple fórmula leucocitaria, impide muchas veces llegar a una conclusión y solo nos proporciona datos relativos.

Todos conocemos el caso del falso negativo que informa el citólogo, con inculpación directa a su competencia - personal subalterno sin que pase por la mente que la falla puede estar en una toma mal ejecutada. Por eso es trascendental recalcar al personal auxiliar, que su labor en la toma de la muestra, es tan importante como los pasos posteriores que tendrá la preparación, hasta su diagnóstico final.

Los mejores resultados se obtienen verificando las tomas citológicas bajo visión directa, previa colocación del espéculum y directamente del ectocérvix. Para el efecto, se puede utilizar un baja lenguas humedecido que se pasa suavemente sobre el ectocérvix. Posteriormente sobre el portaobjetos al que previamente se le ha colocado una gota de solución salina, se desprende el material del baja lenguas con ligeros movimientos de rotación y con este mismo se verifica una extensión suave de izquierda a derecha sin pasar sobre el mismo campo, para evitar la superposición celular. También es recomendable la toma con un escobillón que en su extremo libre lleve un poco de algodón humedecido. Se hacen toques sobre el ectocérvix y posteriormente se rota de izquierda a derecha sobre el portaobjeto. Como la mayoría de los carcinomas cervicales se originan en el límite de los epitelio endo y ectocervical, el escobillón, permite hacer tomas endocervicales que deben extenderse en portaobjeto aparte.

Es muv importante tener en cuenta que lavados vaginales previos, Iubricantes, óvulos y cremas, dan extendidos que no ofrecen seguridad diagnóstica.

\section{Dificultades para la popularización de la coloración de Giemsa}

Quien haya tenido la oportunidad de trabajar citología con la coloración de Giemsa, encuentra la misma seguridad diagnóstica que le ofrece la de Papanicolaou, con un precio centenares de veces inferior. Sinembargo en nuestro medio, casi la totalidad de los Citólogos y Patólogos iniciaron sus estudios citológicos y la practican, con la coloración clásica de Papanicolaou y es sumamente difícil convencer a quien ha encontrado en un sistema, belleza, armonía, seguridad y eficiencia, a que cambie a otro que requiere un poco de entre- 
namiento por la tonalidad de colores y detalles cromáticos.

Para que la coloración de Giemsa brinde toda la seguridad y eficiencia, se requiere que el Citólogo, observe al principio la misma preparación con los dos tipos de coloración, con la seguridad que en poco tiempo, encuentra en la de Giemsa, rapidez, eficiencia y facilidad lo que lo inducirá a usar esta en campañas intensas para la profilaxis del carcinoma cervical.

\section{Resumen y Conclusiones}

1. Quien haya tenido práctica Citológica con la Coloración de Papanicolaou, encontrará en la coloración de Giemsa los mismos caracteres citológicos y la misma seguridad diagnóstica. Es recomendable verificar las primeras coloraciones simultáneamente para mayor facilidad en su familiarización.

2. La Trichomoniasis vaginal que a veces dificulta la interpretación citológica, se hace muy manifiesta con dicha coloración, por ser selectiva para la Trichomona. La Candida albicans se colorea frecuentemente, pero no siempre.

3. No son raros los casos en que las tomas endocervicales presentan Diplococo de Neisser insospechado en el examen clínico y comprobado posteriormente con investigación más adecuada. El Diplococo de Neisser se colorea muy bien con el Giemsa.

4. Permite valorar globalmente el nivel estrogénico pues las características de células profundas basales, para-basales, intermedias y superficiales, son iguales a las que ofrece el Papanicolaou.

5. Evita tener en los Consultorios, Centros de salud etc. frascos con fi- jador, que es costoso, se evapora e incómodo para el transporte.

6. Es mayor el costo del portaobjeto que la misma coloración. No requiere auxiliares especiales, deshidratantes, xiloles etc. En una extensa campaña citológica dirigida a los Centros populares, podríamos colorear unas 50 citologías, por el mismo costo de una de Papanicolaou.

7. El Clínico debe tener en cuenta que su labor en LA TOMA DE LA MUESTRA es tan importante, como que ésta sea interpretada con toda competencia.

\section{BIBLIOGRAFIA}

1 H. SMOLKA, J. SOOST. Compendio y Atlas de Citodiagnóstico Citológico. Edit. Labor. Barcelona. 1966.

2 SCHORR E.: New tecnic for staning vaginal smear. Science. 91 : 579. 1940.

3 PAPANICOLAOU G. N. and TRAUT H. F.: The diagnosis value of vaginal smears in carcinoma of the uterus. Am. J. Obst. Gyn : 42: 193. 1941.

4 A. LINKE. Diagnóstico precoz del cáncer. Coloración de M. G. Giemsa. Edit. Científico Médica. Madrid. 1964.

5 LOPEZ CARDOZO. P. Clinical Cytology using the May Grunwald Giemsa Stained Smear L. Stafleu Leyden (Netherland). 1954.

6 LOPEZ CARDOZO P. Atlas of clinical Cytology using the M. G. GiemsaStained Smear. L. Stafleu Leyden (Netherlands). 1954.

7 L. MONTALVO R. Citología vaginal endocervical y endometrial. Edit. Científico Médica. Madrid. 1964.

8 TERZANO GUILLERMO. Significado de la Citología en la Patología cervical. Simposium Sociedad Argentina de patología cervical uterina y culdoscopia. Buenos Aires. 21-23 Octubre 1965.

9 CUSTER R. P. An atlas of the blood and bone marrow. W. B. Saunders, Philadelphia. London. 1949.

10 AYEE J. E. Cancer cytology of the uterus. Grune Stratton New York, 1951. 
11 FORTEZA BOVER G. K. El diagnóstico por la punción esternal. Edit. J. Morato. Madrid. 1945.

12 BECHTOLD E. and REICHER N. B. The relationship of trichomonas infestations to false diagnoses of squamous carcinoma of the cervix. Cancer. 5: 442. 1952.

13 HOPMAN B. C. Clinical cytology and cytologic research. Miami Post Publishing $\mathrm{Co}$. Miami. 1960.

14 NIEBURGS H. E. Cytology technics for office and clinic. Grun Stratton New York. 1956.

15 PAPANICOLAOU G. N.: Atlas of exfoliative cytology. Harvard University Press Cambridge Mass. 1954.

16 BERTALANFFY E. D. Diagnostic realiability of the acridine orange fluorescence microscope method for cytodiagnosis of cancer. Cancer Res. 21: 422. 1961.

17 NIEBURGS H. E. A comparative study of differente techniques for the diagnosis of cervical carcinoma. Am. J. Obs. Gyn. 72: 511. 1956.

18 LAGRUTTA - LAGENS - QUIJANO. Cáncer del cuello uterino. Formas iniciales. Edit. Intermédica. Buenos Aires. 1966.

19 PAOLA G. Detección preclínica del carcinoma de cuello. Día Médico. 32: 89, 2577. 1960.

20 SAMMARTINO R. Carcinoma in situ del cuello uterino. Sinop. Obst. Ginec. 2: 5: 481. 1955.
21 MAC GREGOR B. Detection of cervical carcinoma in the general population. Gynec. Surg. 18: 6, 97611963.

22 MESTWERD G. Atlas de colposcopie. G. Mason Edit. Paris. 1955

23 KOTTMIER H. L.: Carcinoma cervical con invasión dudosa o inicial. Comunicación IV Congreso Mundial Ginecología. Mar del Pla. ta. 1964

24 AYRE J. E. Técnicas citológicas y métodos usados en la detección del cáncer. Día Médico. 88: 2935. 1955

25 LIMBURG $\mathrm{H}$. Comparasion between colposcopy and cytology in the diagnosis of early cervical carcinoma. Cancer, 12: 416, 1959

26 RUIZ V. LAGRUTTA J. LAGUENS R. QUIJANO F. El extendido grado III en la colpocitología "su relación con la patología cervical. Obs. y Ginec. Latinoamer. 18: 543: 1. 1960.

27 GRANT M. Cytology in prevention of cancer of the cervix. Obst. Gynec. Surv. 18: 6: 974. 1963

28 WIED G. L. Phase contrast microscopy and office technique for prescreening of citology vagina smears. Amer. Jour. Obst. and Gynec. 71: 806. 1956.

29 ANGEL G. Valor clínico e interpretación del examen citológico en ginecología. Boletín del Laboratorio Médico y Ginecológico. Abril 1967. Nọ 18. Cali. 